\title{
CONSCIÊNCIA, VIVÊNCIA E VIDA: UM PERCURSO FENOMENOLÓGICO1
}

\author{
Consciousness, Living Experience and Life: a Phenomenological Reflection
}

Conciencia, Vivéncia y Vida: una Reflexion Fenomenologica

Marcos AuréLIo FERNANDES

\begin{abstract}
Resumo: O artigo propõe um percurso de reflexão fenomenológica, que tem como foco o fenômeno da consciência. Analisando a estrutura intencional das vivências, a qual constitui o traça essencial da consciência, a reflexão remonta até à região fenomenal originária chamada comumente de "vida". Através de uma análise intencional de uma vivência simples, básica e privilegiada, a percepção, chega-se a perceber o caráter de mundanidade da vida. O mundo é sempre mundo da vida e a vida é sempre vida em um mundo. A vivência acontece à medida que acontece vida, que acontece mundo. $\mathrm{O}$ dar-se do eu não pode ser compreendido a não ser em seu enraizamento no acontecer da vida e, concretamente, em seu ser-no-mundo.
\end{abstract}

Palavras-chave: Consciência; Vivência; Vida; Fenomenologia.

\begin{abstract}
The article proposes a course of phenomenological reflection, which focuses on the phenomenon of consciousness. Analyzing the structure of intentional experience, which constitutes the essential feature of consciousness, the thinking goes back to the original phenomenal region commonly called "life". Through an analysis of intentional experience a simple, basic and prime perception, we come to understand the character of mundanity of life. The world is always the world of life and life is always life in a world. The experience happens as life happens, it happens worldwide. Giving up the self can not be understood unless its roots in the place of life and, specifically, on his being in the world.

Keywords: Consciousness; Living Experience; Life; Phenomenology.

Resumen: El artículo propone un curso de la reflexión fenomenológica, que se centra en el fenómeno de la conciencia. Analizando la estructura de la experiencia intencional, que constituye la característica esencial de la conciencia, el pensamiento se remonta a la región fenomenal original comúnmente se llama "vida". A través de un análisis de la experiencia intencional una percepción simple, básico y principal, llegamos a entender el carácter mundano de la vida. El mundo es siempre el mundo de la vida y la vida es siempre la vida en un mundo. La experiencia de la vida sucede como sucede, sucede en todo el mundo. Renunciar a uno mismo no puede entenderse a menos que sus raíces en el lugar de la vida y, específicamente, en su ser en el mundo.

Palabras-clave: Conciencia; Vivéncia; Vida; Fenomenologia.
\end{abstract}

\section{O Problema de uma Investigação Acerca da Cons- ciência}

A fenomenologia é o ver simples do que é simples. Cometeríamos, no entanto, um engano, se pensássemos ser fácil o simples. O simples é o mais difícil, pois exige de nós uma verdadeira conversão do olhar: exige que descubramos, na pobreza daquilo que desprezamos, uma fonte inesgotável de riqueza. O simples é por nós tão desprezado que nem mesmo entra na conta daquilo que, ostensiva e conscientemente, desprezamos. Passa-nos despercebido. Nós o ignoramos.

A via fenomenológica é aquela que nos envia e avia rumo a este próximo e simples. Trata-se daquela luz pri-

\footnotetext{
Texto originalmente apresentado no I Encontro Candango da Abordagem Gestáltica, no Fórum "A Relação Terapeuta-Cliente e o Processo Psicoterápico”, Brasília, 02 de outubro de 2004 (Revisto e atualizado em maio de 2007 e outubro de 2009). Meus agradecimentos às psicólogas, Malu, Irma, Suzana, Denise e Maria Célia, pelas preciosas correções e sugestões oferecidas durante nossa leitura conjunta da última atualização.
}

mordial, em cuja vigência o mundo se torna mundo e nós nos tornamos nós mesmos.

Para nós, que vivemos numa era em que a realidade do real é definida em termos da funcionalidade da relação sujeito-objeto, ou seja, é definida em termos de subjetividade e objetividade, a via fenomenológica se impõe como uma passagem: da consciência para a vida, através da vivência. É a passagem desse caminho que tentaremos percorrer nas páginas que se seguem.

Tentamos, em seguida, nos deixar, pela força do pensamento, reconduzir ao mais originário. O primeiro passo - ainda muito distante da meta, mas sempre um primeiro passo - consiste em voltar-nos das coisas para nós mesmos com nossas vivências. O mundo, o mundo das coisas e o mundo das pessoas, o mundo do real e do ideal, enfim, o todo do ente só se nos faz acessível, só se nos dá, a partir de nossas vivências. O que, de início, chamamos de mundo é o mundo da vida, ou seja, o mundo no qual nós vivemos. Trata-se do mundo das nossas percepções, imaginações, dos nossos sentimentos e desejos, dos nos- 
sos pensamentos, dos nossos atos valorativos e volitivos, do nosso engajamento prático e dos nossos interesses teoréticos. Se nos detemos numa atitude reflexiva a esse mundo acabamos nos dando conta do constante, incessante, imenso fluir destas vivências, de suas efluências, afluências, influências, confluências, refluxos, enfim, da fluência da vida como de um manancial inesgotável, nunca igual a si mesmo. Graças ao olhar da reflexão, podemos contemplar o ir e vir destas vivências, suas co-agitações, ou seja, as cogitações em que se movimenta a nossa vida interior, a vida da nossa consciência.

\subsection{O Tríplice Significado do Título "Consciência" - uma Primeira Indicação Formal do seu Sentido}

Como ponto de partida deste nosso passo na investigação, precisamos ter em mente o tríplice significado de "consciência", a saber, consciência como apercepção das próprias vivências, como o eu fenomenal, que, nesta e para esta apercepção se constitui e consciência como totalidade estrutural intencional dos atos.

Através da reflexão abre-se para nós o horizonte da compreensão do que se chama consciência: a esfera global das conexões de vivências. Tais vivências são captadas de modo peculiar através do que se convencionou chamar de percepção imanente ${ }^{2}$. Eu sou consciente destas vivências. A região global das vivências é aquela que está na possibilidade de se tornar consciente para mim na percepção imanente. Consciência, no sentido de percepção interna, ou seja, percepção do imanente, ou ainda, apercepção, está imediatamente relacionada com o primeiro conceito de consciência, isto é, enquanto região fenomenal das vivências (Heidegger, 1994a, p. 55). Tal região abrange todos

\footnotetext{
Husserl, em vez de falar de percepção externa e interna, prefere falar de percepção imanente e transcendente. Elucidemos, primeiramente, o que ele chama de percepção imanente. Vivendo no cogito, ou seja, vivenciando minhas próprias vivências, normalmente eu não tenho a cogitatio mesma como objeto intencional, mas ela pode vir a tornar-se tal. É que ao cogito pertence, por princípio, a possibilidade de uma mirada reflexiva, naturalmente, porém, na forma de uma nova cogitatio, que se dirige, no modo de uma captação simples, à vivência mesma. Com outras palavras, nós podemos, sempre de novo, voltar o nosso olhar para as nossas próprias vivências: percepções, fantasias, recordações, desejos, sentimentos, etc., e captá-las como objetos desta nossa reflexão. Ora, Husserl chama de atos imanentemente dirigidos ou vivências intencionais imanentemente referidas aqueles ou aquelas, a cuja essência é inerente o fato de que os seus objetos intencionais pertencem, como elas próprias, ao mesmo fluxo vivencial. Portanto, estes são atos referidos a atos (cogitatio que mira a uma cogitatio). Por sua vez, transcendentalmente dirigidas são aquelas vivências onde isto não se dá: atos dirigidos a coisas do mundo circunstante, a vivências de outra consciência, a essências, etc. Pode-se dizer que, no caso da percepção imanente, o perceber e o percebido perfazem essencialmente uma unidade imediata, uma única cogitatio concreta. Só abstratamente é que se pode separar o perceber e o percebido, tão estreita é esta unidade. Aqui o objeto é de tal modo incluído no ato que ele não possui nenhuma independência em relação ao ato como tal. Por outro lado, no caso das percepções de coisas, por exemplo, a coisa percebida é suposta como estando fora de unidade com o perceber mesmo, é percebida justamente como algo de transcendente à consciência mesma (Husserl, 1993, p. 67-69).
}

os conteúdos conscienciais e, de um modo mais determinante, todas as vivências intencionais, ou seja, determinada classe de vivências que possuem a característica de se dirigir a alguma coisa. Cada vivência intencional é caracterizada por ser consciência-de-alguma-coisa. A consciência abrange vivências intencionais atuais e potenciais. Muitas das vivências intencionais permanecem como o fundo vivencial da consciência. Aquelas vivências intencionais, que são trazidas atualmente à luz da consciência, ou seja, que são atuadas de modo reflexo num ego-cogito explícito são denominadas de atos ${ }^{3}$.

Deste modo vem à luz, numa primeira indicação formal, a concatenação do tríplice conceito de consciência:

Consciência é o título regional para o teor integral de vivências anímicas que, enquanto tais, tornam-se acessíveis, por meio da consciência, no sentido do íntimo dar-se conta, e de tal modo que este íntimo dar-se conta pode encontrar uma classe peculiar de vivências que são caracterizadas como consciênciade-alguma-coisa (Heidegger, 1994a, p. 55).

Portanto, o título "consciência”, num primeiro momento, indica uma região de fenômenos, cujo acesso é dado pela percepção imanente ou apercepção, e cuja abrangência abriga em si aquela determinada classe de vivências, ou seja, os atos, que são de fundamental importância para a estrutura da consciência como tal (Heidegger, 1994a, p. 56).

\subsection{Dificuldade de Abrir a Região Fenomenal Indicada pelo Título "Consciência" - Epoché da Investigação Ôntico-Empírica e Aviamento a uma Abordagem Ontológico-Estrutural}

A nossa investigação, inevitavelmente, esbarra num tema de difícil abordagem, um tema que exige de nós esforços fenomenológicos imprescindíveis. Eis que, ao falarmos de "consciência”, abre-se, diante de nós, uma região de fenômenos, que nos é muito familiar, do ponto de vista ôntico, mas que é extremamente difícil de esclarecer do ponto de vista ontológico. Somos colocados ante o desafio de trilharmos um caminho, o nosso, por meio desta região já tanto explorada, mas que mantém, ainda o seu mistério.

Esta região fenomenal, numa amplitude, profundidade e originariedade incomparáveis, constitui, sempre, um campo de interesse especulativo privilegiado para os pensadores antigos e medievais. Na época moderna, a situação não é muito diferente. Desde o início, mais precisamente, desde Descartes, esta região

\footnotetext{
3 Nas "Investigações Lógicas" o nome de ato ainda se confunde com o de vivências intencionais. A distinção agora apresentada foi operada por Husserl após a publicação daquela sua obra fundamental (Heidegger, 1994, p. 55).
} 
fenomenal, sob o título de "consciência", foi objeto de intensos, profundos e fatigantes estudos dos filósofos da época moderna ${ }^{4}$. Os filósofos pós-cartesianos, ao seu modo, procuraram resolver as dificuldades que a abertura desta região fenomenal oferece ${ }^{5}$. Com Husserl ela se tornou o tema fundamental da consideração fe-

\footnotetext{
${ }_{4}$ Com Descartes acontece uma transformação radical da compreensão da totalidade do ente e do homem em meio a esta totalidade. Anteriormente, na idade média e no mundo grego, fazia-se de modo inteiramente natural a experiência da vida interior, ou seja, se experienciava a vida anímica ou intrapsíquica sem que a mesma se tornasse tema de uma reflexão objetivante. Os gregos não conheciam o que os modernos chamam de "consciência". Com

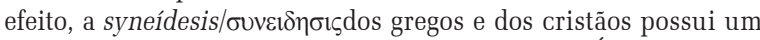
sentido eminentemente moral e não psicológico. É verdade que Aristóteles, ao analisar a percepção, constata que nós percebemos

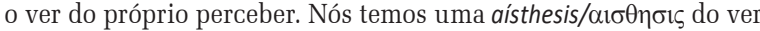
(De Anima Г 2, 425 b 12 sqq). Esta indicação de Aristóteles pode estar apontando para uma direção diferente, porém, daquela da concepção moderna da consciência; diferente e talvez até mais originária do que a da concepção da consciência como autoconsciência: do cogito como cogito me cogitare. Pode-se afirmar que no mundo grego e na idade média ainda não se dá uma cisão entre sujeito e objeto, consciência e coisa, imanência e transcendência. Somente com o advento da ciência moderna, com o predomínio da atitude teorética, observadora, reflexiva, é que emerge a consciência como uma esfera interna contraposta ao mundo como esfera externa e, com isso, uma percepção interior contraposta a uma exterior. A alma ( $\psi v \chi \eta$, anima), a qual no mundo grego e medieval tinha uma extensão, vastidão e uma profundidade muito maior, reduz-se agora à estreiteza e superficialidade da consciência, do ego. O saber a respeito do anímico se transforma, de ciência do espiritual e da razão, no sentido mais originário e vasto destas palavras, em ciência da consciência, uma ciência que ganha o seu objeto na assim chamada experiência interior através da percepção imanente.
}

${ }_{5}^{5}$ Para a filosofia moderna em geral, o cogito é o modo de acesso privilegiado no conhecimento do anímico. Contudo, o que significa isto - o Cogito? O cogito compreende "tudo aquilo que é em mim e do qual eu sou imediatamente consciente" (Descartes, Meditações, Resposta II, definição I). Em duvidando, pensando, negando, afirmando, querendo, sentindo, imaginando, enfim, em toda e qualquer cogitatio eu sou sempre dado a mim mesmo numa evidência imediata. É na experiência do cogito que se me dá de modo imediato a evidência da cogitatio e do cogitatum, bem como a evidência de mim mesmo, do meu ego, uma vez que todo cogito é cogito me cogitare. Neste sentido, o sum do ego é determinado a partir da cogitatio: ego sum res cogitans. Por sua vez, a consciência, enquanto consciência do mundo e consciência de si (autoconsciência), na medida em que é tomada como res é interpretada no sentido da substantia. Mas o ego não é uma substância qualquer. Em relação ao ser de todo e qualquer ente que ele mesmo não é, o ego é por excelência o subjectum, pois é o substractum de todas as cogitationes. A centralidade e o caráter fundamental do sujeito enquanto consciência continuam a ser afirmados no empirismo inglês, como aparece, por exemplo, na tese de Berkeley: esse est percipi. Em Kant a subjetividade é analisada de modo mais profundo a partir da problemática transcendental. Depois dele, o idealismo alemão, aproveitando as deixas de Kant e tentando resolver as suas aporias, caminhou para uma metafísica do eu. Assim, para Hegel a consciência é o ponto de partida da reflexão filosófica. Quando a consciência se desenvolve de forma a conquistar a sua verdade plena (conceito), então ela se torna espírito. Antes, porém, ela deverá ter se tornado autoconsciência e razão. A autoconsciência é a superação da consciência. É que a consciência supõe uma relação de sujeito-objeto onde o objeto está fora dela mesma, como outro dela, como o independente. A autoconsciência é justamente a supressão desta alteridade e exterioridade: a verdade da consciência é a autoconsciência, e esta é o fundamento daquela; de tal modo que na existência a consciência de um outro objeto é autoconsciência; eu sei o objeto como meu, por isso, neste objeto eu sei a mim mesmo. nomenológica ${ }^{6}$. A partir dela, como de um positum, desenvolveu-se a ciência positiva, de caráter experimental, que passou a ser denominada de psicologia ${ }^{7}$. De início, o que mudou foi a impostação fundamental da investigação. Numa época em que reinava a antimetafísica, ou seja, a hostilidade a tudo quanto, por assim dizer, cheirava a especulação e a conceituação; numa época em que a palavra de ordem era ir aos fatos da experiência, as ciências experimentais celebraram o seu triunfo e a psicologia tentou emergir, como tal, a partir de um fundo, malgrado seu, metafísico de materialismo, cientificismo, positivismo, mecanicismo e biologismo. Através de um demorado processo, em que colaboraram diversos pesquisadores, a psicologia, assim ao menos parece, atingiu o grau de ciência experimental no projeto científico de Wundt ${ }^{8}$. Dizemos \begin{tabular}{l}
\hline${ }_{6}$ A fenomenologia em Husserl caminha na direção de uma fenome- \\
nologia da consciência ou da subjetividade transcendental. Nós \\
caminharemos, seguindo os passos da investigação fenomenológica \\
de Heidegger, para além de uma fenomenologia da consciência e \\
da subjetividade transcendental. Deter-nos-emos nela somente à \\
medida que esta constituir, para a nossa reflexão, uma espécie de \\
antecâmara que nos conduz a um âmbito mais originário da feno- \\
menologia. Não deixaremos de aproveitar as suas deixas e, quando \\
for necessário, não deixaremos de apresentar as devidas críticas que \\
justificam a tomada de outro rumo da reflexão fenomenológica. \\
No século XIX as ciências naturais começam a conquistar a “cidade \\
fortificada” da consciência, até então em poder da filosofia. Elas \\
penetram, com seu método próprio, numa região, que, até então, \\
era explorada somente de modo filosófico. Já o empirismo inglês \\
abandona um estudo metafísico da alma (de sua substancialidade, \\
espiritualidade e imortalidade) e assume uma abordagem empírica \\
da mesma. Lança-se como mote da investigação: "não ciência da alma \\
como uma substância, mas ciência das manifestações anímicas, \\
daquilo que se dá na experiência interior”.
\end{tabular}

É na Alemanha que a psicologia dá passos decisivos na direção de se tornar uma ciência experimental. O movimento nesta direção se dá lentamente com o trabalho de alguns pesquisadores, antecessores de Wundt. Assim, Herbart, aluno de Fichte, contra a afirmação de Kant, de que uma psicologia enquanto ciência empírica seria impossível, pois ficaria sempre no nível da descrição e não alcançaria nunca o rigor matemático que caracteriza as ciências naturais, ousou apresentar um programa de ciência da alma humana onde a matemática, ou seja, a mensuração e o cálculo, tivesse uma importância decisiva. Tirando o objeto temático da psicologia do domínio do qualitativo e transferindo-o para o domínio do quantitativo, ele trabalhou na elaboração de uma teoria da mensuração dos fenômenos psíquicos. Assim, ele reconduziu todo acontecimento psíquico a um movimento de simples representações no espaço vazio da consciência, sob influências impulsivas e repulsivas. Johannes Müller, para quem a psicologia deveria estar em íntima conexão com a fisiologia (nemo psychologus nisi physiologus), lança a teoria específica dos nervos: a qualidade das sensações que recebemos não depende do tipo de estímulo (mecânico, elétrico, luminoso) que é exercitado sobre os órgãos dos sentidos, mas sim do tipo de órgão sensorial que é excitado (nervos óticos: sensações visuais; nervos auditivos: sensações auditivas, etc). Helmholtz, aluno de Müller, fundou a fisiologia ótica e acústica, sempre em conexão com supostos problemas da teoria do conhecimento: inferiu que as nossas sensações não são imagens dos objetos do mundo externo, mas são apenas sinais, índices daquilo que ocorre fora de nós. E. H. Weber descobriu a lei que leva o seu nome, ou seja, a lei sobre o nexo entre a grandeza do estímulo e a "grandeza da sensação": a intensidade da sensação é proporcional ao estímulo. A partir desta descoberta Fechner desenvolveu a "psicofísica", ou seja, a teoria da mensuração dos fenômenos psíquicos e sua funcional dependência das grandezas dos estímulos: descobriu que os estímulos crescem em progressão geométrica, enquanto as 
"ao menos parece", uma vez que a discussão sobre a cientificidade e o caráter de rigor do método desta ciência é uma questão que deve permanecer em aberto e que não podemos discuti-la aqui. Em todo o caso, foi Willhelm Wundt quem fundou o primeiro instituto para psicologia experimental em Leipzig. Ali ele e seus alunos (europeus e americanos) dedicaram-se experimentalmente a quatro campos de pesquisa: a psicofisiologia dos sentidos, o tempo de reação aos estímulos, a psicofísica e a associação mental. Ocupou-se também com as atividades psíquicas superiores (processos intelectivos e volitivos). Intuiu que estas não poderiam ser explicadas a partir de sensações e por isso introduziu a "síntese criativa": o resultado de uma combinação de elementos psíquicos não é a mera soma destes, mas alguma coisa de nova e original em relação àqueles. Com Wundt se afirma a tendência fundamental da moderna psicologia "experimental” que consiste na explicação dos acontecimentos psíquicos através de uma conexão unitária que tem o caráter de lei e através da regulação mediante condições fundamentais últimas, que têm suas raízes em conexões últimas de elementos psíquicos (Heidegger, 1993, p. 213).

Poderíamos nos sentir tentados a seguir uma investigação da consciência, baseando-nos nos resultados mais recentes da psicologia experimental sobre isso. No entanto, tal procedimento, talvez, ser-nos-ia contraproducente, não só por causa da grande variedade de correntes ou abordagens, que constitui hoje o que chamamos de psicologia, mas sobretudo porque a direção de nossa investigação não é ôntico-positiva e sim fenomenológico-ontológica ${ }^{9}$. Por isso, vamos operar uma epoché em relação às ciências positivas, precisamente, em relação à psicologia, esta ciência que, em mais de uma perspectiva e nas suas várias configurações guarda relação com a fenomenolo-

sensações em progressão aritmética. Isto quer dizer que a relação entre estímulos e sensações pode ser representada por uma curva logarítmica (Heidegger, 1993, p. 213).

9 Aqui não podemos entrar numa apresentação aprofundada da relação entre fenomenologia e psicologia. Damos apenas algumas indicações a respeito do assunto. Antes de tudo convém lembrar que a fenomenologia de Husserl surge a partir de um confronto contra o psicologismo, ou seja, contra a pretensão de se fundar a lógica sobre a psicologia. A refutação do psicologismo na lógica, Husserl efetua no primeiro volume das "Investigações Lógicas" (1900), que se intitula "Prolegômenos para a lógica pura". No famoso artigo da revista Logos (1910/11), intitulado "Filosofia como ciência de rigor", Husserl combate o naturalismo e o historicismo. Ali Husserl afirma a necessidade de uma ciência da consciência, ou melhor, de uma fenomenologia da consciência, a qual deveria contrastar com a ciência natural da consciência, ou "psicologia exata", que incorre no erro capital de uma naturalização da consciência. Nasce, então, a compreensão de uma tarefa singular: fundar uma psicologia originária, uma psicologia que não fosse mais ingênua, fenomenologicamente falando. O método experimental fica apenas no nível das conexões de fatos e pressupõe aquilo que nenhum experimento é capaz de realizar: a análise da consciência mesma. Somente uma fenomenologia sistemática da consciência seria capaz de dar às investigações positivas e empíricas da psicologia uma base segura, conceitos fundamentais claros e direções metodológicas apropriadas à investigação da vida psíquica. gia, enquanto fenomenologia transcendental, ou seja, fenomenologia eidética da consciência ou da subjetividade transcendental ${ }^{10}$. Tentaremos abrir um caminho, portanto, abstendo-nos de enveredar pelos âmbitos das ciências positivas, voltando-nos para o mundo da vida, melhor, para o mundo da experiência pré-científica.

Trata-se de um caminho de investigação filosófica. A intencionalidade é nosso fio condutor. Só que a primeira instância onde se nos apresenta a intencionalidade é já problemática e deve ser submetida a uma crítica, visando um aprofundamento daquilo que esta descoberta nos revela. De início, a intencionalidade se nos apresenta como uma estrutura das vivências que constituem a consciência. Em vez de enveredar-nos inopinadamente, de improviso, na direção de uma fenomenologia pura e simples da consciência ou de uma subjetividade transcendental, queremos nos deter naquilo que chamamos de vivências e submeter este dado a um exame mais atento, pois poderia ser uma suposição tanto fecunda como fatal para a nossa reflexão. Sem considerarmos a ambigüidade que este título "vivência” traz consigo, poderíamos incorrer em aporias das quais dificilmente poderíamos escapar.

\footnotetext{
${ }^{10}$ No volume I das "Idéias para uma fenomenologia pura e uma filosofia fenomenológica" (publicado em 1913 no Anuário para filosofia e investigação fenomenológica), Husserl compreende a fenomenologia como a essência da própria filosofia enquanto ciência rigorosa e originária em seu método, ou seja, como ciência fundamental da filosofia, com outras palavras, como filosofia primeira. "Fenomenologia pura" quer dizer: "fenomenologia transcendental". Transcendental, porém, é a subjetividade que conhece, age, põe valores. A fenomenologia conserva as vivências da consciência (esta é o resíduo fenomenológico que permanece, uma vez que é operada a epoché de todo conhecimento posicional) como seu âmbito temático, agora, todavia, na sondagem sistemática projetada e assegurada da estrutura dos atos das vivências, juntamente com a sondagem dos objetos, no tocante à sua objetualidade, que são vivenciados nos atos. À consciência transcendental, tornada acessível através do método das reduções fenomenológicas (redução eidética e redução transcendental), corresponde o eu transcendental, o eu mais íntimo no eu, qual pólo subjetivo dos atos egóicos, o eu constituinte do próprio eu constituído (eu empírico - personalidade), o eu que está à base da constituição do próprio mundo, o pólo subjetivo ao qual se refere o mundo constituído enquanto pólo objetivo, o núcleo a partir de cuja atividade primordial surge a constituição da totalidade do que pode se tornar acessível no cogito. Uma tal ciência de essências (eidética), uma tal fenomenologia da consciência ou da subjetividade transcendental, é o pressuposto para a fundação de toda e qualquer ciência de fatos (empírica), que deve pressupor sempre uma compreensão da constituição de seu âmbito objetivo temático. Trata-se de uma ontologia fundamental e universal, à qual deve se subordinar toda ontologia regional. À medida que as ciências positivas (como a psicologia, por exemplo) se fundassem fenomenologicamente nas suas ontologias regionais e estas na ontologia fundamental e universal, que coincide, ao ver de Husserl, com a fenomenologia transcendental, então se realizaria uma reforma geral do saber e o início daquilo que gerações anteriores sonharam e chamaram de "mathesis universalis" (Descartes, Leibniz). As bases para uma psicologia fenomenológica estão apresentadas no volume IX da Husserliana. Aí se encontram os textos de preleções dadas por Husserl em 1925, com o título de "Psicologia Fenomenológica", além das conferências de Amsterdam (1926) sobre o mesmo tema e do artigo, destinado à Enciclopédia Britânica (1928), que marca o rompimento entre Husserl e Heidegger.
} 


\section{A "Vivência" como um Problema Fenomenológico Privilegiado, ou seja, como Chance de Abrir a Região Fenomenal da Vida}

A nossa decisão de operar uma epoché em relação ao saber científico, no caso específico, em relação à psicologia, enquanto ciência positiva, constitui um rompimento com o primado do teorético na consideração da vida. Tal rompimento não é motivado tanto em função de ceder a um primado do prático, mas é motivado, sobretudo porque toda esfera do teorético já pressupõe o chão do âmbito pré-teorético, toda a dimensão do saber científico já pressupõe a dimensão, mais originária, da vida précientífica. Tal dimensão nós chamamos, de modo ainda indeterminado, de mundo da vida.

Nós consideramos que a fenomenologia é a ciência originária desta dimensão originária, aqui denominada, provisoriamente, de mundo da vida. Ao investigar sobre a intencionalidade nós tentaremos reconduzir esta investigação ao mundo da vida. Tomando o atalho que nos desvia de uma fenomenologia transcendental da consciência não estamos querendo retornar para aquém do saber crítico, voltando-nos para a direção de um realismo ingênuo, mas estamos querendo ir, por um caminho mais curto, talvez, para aquela dimensão ainda mais originária do que a dimensão da consciência e da subjetividade transcendental: a dimensão para a qual acenamos - e por agora só podemos oferecer um aceno - com a expressão "mundo da vida".

Quando pusemos em relevo a intencionalidade como estrutura das vivências, como o estrutural dirigir-se-aalguma coisa, como o mirar-a-alguma-coisa, o ser-consciência-de-alguma-coisa, não questionamos o conceito de vivência e sua relação com a vida, relação que se infere da própria palavra. Antes, portanto, de seguir adiante seguindo o fio condutor da intencionalidade, é preciso ver o que isto, que chamamos de vivência, cuja estrutura a priori é constituída pela intencionalidade, tem a ver com a vida. Deste modo, o título "vivência" constitui, para nós, um problema privilegiado, que pode nos abrir um acesso para a profundidade, amplidão e originariedade da vida ${ }^{11}$.

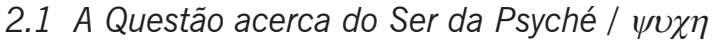

Ao colocarmos o problema da "vivência", a nossa primeira tendência é a de interpretá-la como fenômeno psíquico e, por sua vez, interpretar o psíquico no senti-

\footnotetext{
${ }^{11}$ Usamos, aqui, a palavra "problema”, numa acepção diferenciada daquela própria do uso comum. "Pro-blema" vem do grego pro-bállein: "pro-" indica, aqui, a abertura da possibilidade de manifestação; “-bállein”, o lançar e o jogar, o acertar e o atingir. "Pro-blema” é, pois, tomado na acepção de um movimento que, no próprio lance de jogo, atinge a si mesmo, abrindo-se como a possibilidade de uma manifestação. Decidimos, pois, assumir a vivência como um problema, ou seja, como aquela instância onde pode abrir-se, para nós, a manifestação da vida no seu sentido mais originário.
}

do do objeto da psicologia ${ }^{12}$. É certo que a intencionalidade não é algo de físico, mas isto não significa que seja algo de psíquico, nem necessariamente uma junção do psíquico com o físico. Este modo de representar a intencionalidade representaria um extravio. É que, com "físico" e "psíquico" nós entendemos, usualmente, duas regiões do ser, cujos modos de ser são diferenciados, mas que pressupõem um comum sentido do ser que permanece inquestionado: ser como ocorrência, ser como ser simplesmente dado.

Com efeito, o psíquico, no sentido da psicologia, é um ser, contudo, não um ser em repouso, mas um ser em constante alteração, uma conexão de processos que decorrem no tempo, um ser caracterizado justamente pela temporalidade, que não preenche espaço, uma esfera de ocorrências que pode ser desmontada reconduzindo-as a processos elementares que se referem a fatos fundamentais (sensações, representações, etc). A construção de processos superiores é regulada por legalidades que regem o processo psíquico como tal e que, portanto, explicam o psíquico nele mesmo. A atomização e a construção dos processos psíquicos pressupõem a unidade do psíquico como uma concatenação objetiva, ou seja, de processos ou elementos que se dão a modo de coisas, ocorrências, fatos, só que de natureza psíquica e não física. Tais processos podem ser "descritos" empiricamente e "explicados" com base nas leis que os regem, leis psíquicas, diferentes das leis físicas, mas, no fundo similares, pois também no âmbito psíquico se depara com algo como "energia psíquica”, "causalidade psíquica”, etc (Heidegger, 1987a, p. 61).

Deste modo, a tendência de fundo é interpretar aquilo que os gregos, de modo e originário, chamavam de

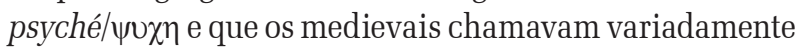
de anima, animus, spiritus, intellectus, mens, o que indicava uma gama de fenômenos pertencentes ao mundo do si-mesmo, na direção do que os modernos chamam de o psíquico. Tende-se - ao menos de início e como tendência dominante - a uma psicologia sem alma. Desalmando-se o psíquico, o mesmo é conduzido à dimensão do meramente biológico, onde o vivente é restringido à dimensão do orgânico. Por sua vez, através de um processo de desvitalização, o psíquico é reduzido a uma espécie de química mental: pode-se atomizar os processos psíquicos reconduzindo-os a elementos últimos e simples; do mesmo modo, pode-se estabelecer as diversas composições possíveis de se ocorrer na esfera do psíquico. Atomizando e decompondo-se a química mental, pode-se descobrir, em última instância, uma espécie de física, de dinâmica psíquica, e estabelecer as leis que regem a energia psíquica e que assim determinam o comportamento do indiví-

\footnotetext{
${ }^{12}$ Desta maneira, Brentano chegou à descoberta da intencionalidade justamente tentando definir o psíquico em oposição ao físico, fenômeno psíquico em contraste com fenômeno físico, o objeto da psicologia em contraste com a natureza em geral, enquanto objeto das ciências naturais.
} 
duo da espécie animal que é o homem. Esta, ao menos, é a tendência dominante de uma ciência do psíquico que se compreende a si mesma a partir do padrão das ciências naturais.

Mas, o que acontece se nós andarmos em outra direção e, em vez de permanecermos na representação naturalista do psíquico, apropriarmo-nos da descoberta do sujeito? Pode ser que a situação melhore, contudo, ainda não nos garante um ponto de partida originário. Com efeito, um processo psíquico como tal, enquanto coisa isolada, não explica nada, e processos psíquicos, como sensações, percepções, representações da memória, só são esclarecidos, caso decorram em um sujeito que conhece, sente, age, põe valores, se relaciona, etc. Certamente, com o sujeito, a conexão objetiva, factual, do psíquico ganha um ponto de unidade também ele factual, objetivo, mas com isso permanecemos ainda no mesmo nível do posicional. Continuamos na esfera do ser enquanto ocorrência.

Assim, para se compreender bem a intencionalidade, enquanto estrutura das vivências, seria necessário

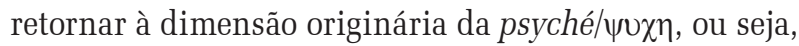
da vida. Mas isto só é possível se compreendermos a vida de modo não biológico (é altamente questionável se a biologia moderna sabe alguma coisa acerca da vida) e a psyché de modo mais originário do que o que usualmente se entende por psíquico, no âmbito da psicologia em geral (é altamente questionável se a psicologia moderna sabe alguma coisa acerca da psyché).

\subsection{O Modo de Ser da Vivência: não Coisa, mas Comportamento da Vida - A não Referência da Vivência ao Meu Eu, Enquanto "Este" Eu; O Enraizamento do Meu Eu no Acontecer da Vida Enquanto Tal}

Toda vivência é vivência de alguma coisa e este vivenciar tem o modo de ser de um dirigir-se-a-alguma-coisa, ser-consciência-de-alguma-coisa, mirar-a-alguma-coisa. Dito de modo ainda mais formal: todo vivenciar é vivenciar-alguma-coisa, sendo, ao mesmo tempo vivência-davivência, consciência-da-consciência: autoconsciência enquanto consciência de alguma coisa. Em percebendo, em imaginando, em sentindo, em recordando, em querendo, em pensando, eu vivencio alguma coisa, ao mesmo tempo em que vivencio, cada vez, a vivência mesma.

Caso nós dirijamos um olhar simples para o que de modo simples e imediato se dá cada vez na vivência, não apreenderemos de modo algum um processo, uma ocorrência, algo de objetivo, de factual. O considerar a vivência como algo que ocorre em mim, como um processo na minha psique, como uma ocorrência psíquica em geral, já é uma interpretação que não apreende o que se dá, de fato, em meu viver, cada vez que tenho, isto é, realizo ou sofro, esta ou aquela vivência. A coisificação e objetivação da vivência já é um cair fora da dimensão originária em que vivência se dá como vivência: da dimensão originária da vida.

Em toda e qualquer vivência, cada vez, eu me comporto com, eu me dirijo a, me refiro a alguma coisa. Por sua vez, este comportar-se-com tem o modo de ser de um mirar-a, de um ser-consciência-de-alguma coisa. A rigor, somente um ente dotado do modo de ser intencional é que pode se comportar-com, relacionar-se-com, dirigirse-a alguma coisa. Podemos chamar de comportamentos as vivências intencionais. Mas, aqui, convém prevenirnos de interpretar tais comportamentos de modo comportamentalista, ou seja, como mecanismos psíquicos. Isto significaria, mais uma vez, perder de vista a essência intencional dos mesmos. A percepção é um comportamento. Assim também o são os demais atos ou vivências intencionais: a recordação, a imaginação, o amor, o ódio, o querer, o desejar, o pensar, etc.

Eu me comporto: em todo e qualquer cogito como Cogitante, ou seja, na percepção como percipiente, no amor como amante, no ódio como odiante, no desejo como desejante, no pensar como pensante, e assim por diante. Mas há algo de estranho nisto tudo: vendo, de modo simples, o que se dá, cada vez, em cada vivência, nunca se mostra algo como um "eu”. É como se, em vez de dizer "eu vivencio", se pudesse dizer "vivencia-se" e este vivenciar é cada vez um vivencia-se-alguma-coisa. É como se o "sujeito" de cada vivência fosse, não tanto eu mesmo, mas a vida. A percepção é vida percipiente, a imaginação é vida imaginante, o pensamento é vida pensante, a pergunta é vida perguntante, o desejo é vida desejante.... Mas, poder-se-ia objetar, não sou eu que vivo cada vez esta vida que se dá através dos diversos comportamentos que eu assumo, realizo ou sofro? Certamente. Eu, contudo, com a minha consciência, com a minha subjetividade, já estou enraizado nesta vida, que vive em mim, que eu vivencio, na qual eu vivo e sou vivido. Os comportamentos, antes de serem meus comportamentos, são comportamentos da vida: modos de a vida se portar, se trazer a si mesma, em mim e através de mim.

Todo vivenciar alguma coisa é também e antes de tudo um viver, que se abre para alguma coisa, um desabrochar da vida. Que cada vivência, enquanto auto-efetivação e auto-afeição da vida, precise, cada vez, de um eu individual para se concretizar, já não é um dado particular, ou seja, já não é um dado, que diz respeito apenas ao meu eu individual, mas é um dado universal, pois toca a todos os eus. Assim, o que chamamos de "eu" não é a fonte da vivência, mas apenas uma sua passagem; é certamente uma condição, necessária, mas não suficiente. Que a vida, através do desabrochar e da fluência de suas infindas vivências, constitua, cada vez, um eu, que, como subjetividade empírica, individual, com esta ou aquela fisionomia e identidade particular -, este acontecimento não depende, em última instância, de cada eu individual, não é algo que lhe está ao arbítrio, mas o seu ser "eu" já o pressupõe. Com outras palavras: 
Justamente porque o sentido da vivência é sem referência ao meu eu (enquanto este eu, que é assim e assim) é que, no entanto, não se há de ver, na mirada simples, a referência de certo modo necessária ao eu e o eu mesmo (Heidegger, 1987a, p. 69).

Em que medida a referência ao eu pertence, necessariamente, ao sentido da vivência, embora não apareça no horizonte de visibilidade daquilo que a vivência vivencia? À medida que a vivência é, cada vez, minha vivência, isto é, a vivência que se apresenta aqui, em mim, e que eu vivencio agora ${ }^{13}$. Eu estou aí, junto da vivência que vivencio, eu vivo nela, ela pertence à minha vida, não obstante seja, segundo o seu sentido, desvinculada de mim, sim, de certo modo, absolutamente distante de mim (Heidegger, 1987a, p. 69).

Eu posso fazer a experiência das minhas vivências, e de mim mesmo se dando sempre junto com minhas vivências, mas toda tentativa de objetivar a vivência e o meu eu, de apreendê-los como uma coisa, um processo, um fato, um objeto, resulta vão, pois falsifica o sentido mais próprio de ser destes fenômenos. O vivenciar não é nenhuma coisa, não é também uma ocorrência, algo que começa e termina como um pro-cesso. O "comportar-se com” não é uma coisa à qual se ajunta uma outra coisa, o "algo" com que se comporta. Na verdade, o vivenciar e o vivenciado, como tais, não são nunca acoplados como objetos que meramente ocorrem, que brutalmente existem. Esta não coisalidade da vivência, do eu, da intencionalidade é já uma boa indicação para nossa reflexão, embora seja ainda uma indicação apenas negativa, que precisa de ulterior clarificação.

\subsection{Vivência: Não Processo, mas Evento - A Signifi- cância do que se Manifesta na Vivência e para a Vivência e o Dar-se da Vivência como o Acontecer do Mundo da Vida}

Tentemos tornar presente, de modo mais claro, aquilo que estamos dizendo. Façamos esta presentificação com base numa vivência concreta: a vivência da percepção.

Quando, neste momento, falamos de "percepção" estamos pensando num caso bem concreto de percepção: a percepção de uma coisa, que se dá aqui, diante de mim, no meu ambiente de trabalho, no meu mundo circuns-

\footnotetext{
13 Só que seria errôneo interpretar o “aqui” no sentido da espacialidade do espaço físico e o "agora" no sentido da temporalidade do tempo físico. O “aqui” se refere a uma espacialidade originária, assim como o "agora” pertence a uma temporalidade originária, que não podem ser compreendidos a partir da espacialidade e da temporalidade das coisas. Por outro lado, também seria problemático interpretar o "aqui" e o "agora" no sentido de uma espacialidade e temporalidade psíquica, se continuamos compreendendo o psíquico a partir do físico. Há que se interpretar a espacialidade e a temporalidade da nossa presença no seu modo de ser mais próprio e só aí poder dizer o que significa uma provável espacialidade ou temporalidade “psíquica”. O caminho contrário é inviável.
}

tante. Tentemos ver de modo simples o que acontece com e na percepção de alguma coisa, no caso, na percepção desta mesa onde escrevo, desta escrivaninha. Para poder ver de modo simples, porém, é preciso afastar toda interpretação, que já parte de determinados pressupostos inquestionados: tal como o pressuposto de que a percepção é algo que se dá numa relação de sujeito-objeto, de que é um resultado da combinação de sensações, é o produto de estímulos nervosos, etc. Tentemos ver de modo imediato o que se dá de modo imediato.

Entrando no meu quarto, eu vejo a minha escrivaninha. O que vejo, quando vejo a minha escrivaninha? Vejo uma coisa de madeira, de cor amarelada, alta e larga tantos centímetros? Não, eu vejo a minha escrivaninha: este móvel útil como apoio para escrever; móvel que se dá junto com outros móveis deste quarto, tais como cadeiras e estante de livros; móvel que traz em si um computador, uma luminária, lápis, caneta, papel, disquetes, livros. Se um visitante entrar em meu quarto, verá esta mesa da mesma forma e saberá: ali está a mesa onde meu amigo trabalha, onde ele escreve sua tese, onde estuda e prepara suas aulas. É verdade que, tanto eu quanto meu amigo vemos esta mesa como uma coisa feita de madeira, de cor amarelada, que possui esta extensão, este cumprimento, esta largura. Mas não é assim que, primeiro vejo esta coisa como mera coisa de madeira, para então colar sobre ela um significado: o de escrivaninha. Vejo desde já uma escrivaninha, este móvel que tem esta utilidade específica: servir de apoio para ler e escrever. Vejo-a como este móvel que aparece junto de outros móveis. Vejo de que ele é feito, se está bem conservado ou não, se precisa de uma nova pintura ou não. Mas isto nada tem a ver com ver a escrivaninha como um mero objeto que ocorre aí no espaço, com esta ou aquela extensão, esta ou aquela configuração. Ao ver esta escrivaninha eu não a vejo como mera coisa extensa, mas como coisa-de-uso. Eu não a vejo como uma coisa, que primeiro aparece na sua brutal existência, no existir enquanto ocorrer nu e cru, mas eu a vejo como coisa com este significado: o de ser escrivaninha. O significado não é algo que se cola à coisa de modo posterior à percepção da coisa na sua crueza. A coisa, percebida como coisa de uso, já aparece com um significado: escrivaninha. Contudo, vamos supor que alguém nunca tenha visto uma escrivaninha na sua vida, não saiba ler nem escrever. Ao entrar no meu quarto ele verá a escrivaninha como mera coisa de madeira, os livros como papéis tingidos com manchas pretas, o computador como uma caixa de metal qualquer? Certamente que não! Ele verá "trens”, "troços” que, para ele, não servem para nada. Mas um "troço" não é uma mera coisa. Um "troço" é uma coisa de uso que adquire a significação de importunidade, ou cuja referência de uso, a referência do seu "para-que-serve" permanece indeterminada. Pode ser que este alguém, sendo meu amigo, me respeita e respeita o meu trabalho. Neste caso, ao entrar no meu quarto ele irá ver o meu ambiente de trabalho com to- 
das as suas "tralhas" e, mesmo não sabendo o que fazer com elas, irá considerá-las como coisas que fazem parte do mundo deste amigo, deste amigo que, diferente dele, passou anos estudando na escola e até hoje gosta de estudar, que sempre está preocupado em escrever...

Na vivência da percepção desta escrivaninha algo se me dá a partir do meu mundo circunstante imediato. Trata-se deste algo mundano-circunstante, a saber, a escrivaninha, que aparece, cada vez, a partir desta ou daquela perspectiva, nesta ou naquela iluminação, dentro deste ou daquele fundo perceptivo. Trata-se desta escrivaninha, que nunca aparece isolada, mas sempre dentro de uma conexão instrumental: livros, papéis, lápis, caneta, computador... No entanto, mesmo se eu visse esta escrivaninha em outro lugar, jogada em qualquer parte, eu a veria como algo, que foi jogado fora ou como algo, que está fora do lugar. Sempre, portanto, como algo, que remete a outros algos, com que mantém uma relação de referência instrumental. Todas estas coisas, que vejo no meu quarto, juntamente com a escrivaninha, não são meras coisas, que existem primeiro para depois ter um significado. São coisas, que já aparecem como tendo este ou aquele significado. O significado da coisa, o seu ser-paraisso ou para aquilo, ou o seu indeterminado ser-para, é o que percebo por primeiro, quando vejo uma coisa de uso dentro do meu quarto ${ }^{14}$.

Vivendo, cada vez, num mundo circunstante, sempre e por toda a parte, tudo é dotado do caráter de mundo, tudo é significativo para o mundo da vida. Por toda a parte e sempre o mundo acontece como mundo (Heidegger, 1987a, p. 70-73).

$\mathrm{O}$ mundo acontece. Está sempre acontecendo. A vida acontece. Está sempre acontecendo. Mundo e vida se pertencem. O mundo é mundo da vida. O mundo é, cada vez, o mundo vivenciado por mim. Eu sou, cada vez, no vivenciar o acontecimento do mundo. Em cada vivência, no desabrochar de cada evento da vida, eu já sou lançado no mundo, eu já estou no aberto do mundo. O meu eu vibra, ressoa, em cada vivência. E assim, o eu de cada um está sempre vibrando, oscilando, ressoando com cada vivência que acontece no viver de cada um:

Só no ressoar-com de cada eu próprio é que se vivencia um algo mundano-circunstante, é que acontece

\footnotetext{
${ }^{14}$ Faz parte da essência intencional (intentionales Wesen) de todo o ato (Akt) o seu sentido apreensional (Auffassungssinn), juntamente com a sua modalidade própria de ser consciência-de (Bewusstseinsweise). Com efeito, cada modalidade de ser-consciência-de é uma modalidade de ter-em-mira-alguma-coisa, sendo que, este "alguma coisa" jamais se dá como algo neutro, mas sim como um algo determinado, que apresenta este ou aquele significado para a consciência. Neste sentido, a intencionalidade é constituinte da significância de tudo aquilo que pode ser vivenciado na experiência da vida. Todo ato é, enquanto intencional, um dar significado àquilo, que, nele e para ele, se manifesta (bedeutungsverleihender Akt). Por conseguinte, todo o ato, enquanto intencional, possui a sua essência significacional (bedeutungsmässigen Wesen). Todo "alguma coisa" vivenciado terá, pois, o sentido de significância (Bedeutsamkeit). O mundo será, portanto, a totalidade da significância, em que eu, cada vez, vivo.
}

mundo, e onde e quando acontece mundo para mim, eu estou de alguma maneira bem ali, juntinho (Heideger, 1987a, p. 73).

Tudo quanto se dá com o mundo tem o poder de me tocar, de me afetar, de me afeiçoar. Somente a mera coisa, o mero objeto, resultado de uma desmundanização do mundo e de uma desvitalização da vida, não me toca. Ela permanece o indiferente ${ }^{15}$. Ao contrário, quando o mundo se dá - e ele se dá sempre, pois mesmo quando nós operamos uma desvitalização da vida e uma desmundanização do mundo em favor de uma objetivação que se contenta em observar meras coisas, mesmo ali o mundo é o chão a partir donde isto se torna possível - quando o mundo acontece, ali algo me vem de encontro, algo me toca, me provoca, me fascina. Disto é testemunha a poesia, a arte, a experiência religiosa, o pensar filosófico, que se compreende como tal.

A primeira condição para compreendermos melhor a intencionalidade é não interpretarmos as vivências como ocorrências, ainda que como ocorrências psíquicas, é não objetivá-las, não representá-las, não fixá-las. Elas não são coisas. Não são nem mesmo processos psíquicos. Vendo, de modo simples, a vivência e apreendendo-a assim como ela se dá, de modo imediato, eu não vejo nada de psíquico. Vivência não é algo de psíquico, uma ocorrência que se passa na esfera da minha consciência, como em uma cápsula, algo de que me aproprio só posteriormente e desde fora. Aliás, aqui não tem mais sentido falar de um "dentro" em oposição a um "fora", como não tem mais sentido falar de "psíquico" e de "físico".

Entretanto, as vivências acontecem. Nelas e com elas está se dando constantemente o acontecimento da vida, o acontecimento do mundo, o acontecimento do mundo da vida, do meu viver-no-mundo. A vida é sempre mundana ${ }^{16}$. É sempre historial ${ }^{17}$. Neste sentido, podemos compreender a vivência intencional como evento. O processo é apenas uma pálida reminiscência do evento. Um resto, um algo que sobrou da desvitalização da vida, da desmundanização do mundo. $\mathrm{O}$ vivenciar não é um processo que passa por mim e que eu posso representar como

${ }^{15} \mathrm{O}$ "neutro", o in-diferente da desmundanização, contudo, ainda é um modo de significância.

16 Aqui o adjetivo "mundana", referida à vida, não tem a conotação usual que esta palavra recebe a partir de um juízo moral ou a partir de uma concepção religiosa ou sacral qualquer. É tomada no seu sentido literal: trata-se daquilo que guarda uma relação íntima com o mundo. Por sua vez, não deve também ser entendida no sentido daquilo que ocorre dentro do mundo. Aqui a palavra vida não significa algo que ocorre dentro do mundo, uma propriedade de entes que nós chamamos de viventes (plantas, animais) e que ocorrem dentro do mundo. Ao contrário, aqui a palavra vida está acenando para o acontecer do mundo nele mesmo, no seu próprio.

17 Por enquanto é inevitável que palavras primordiais como "mundo" e "vida" permaneçam indeterminados. Vamos dando apenas alguns acenos para, na medida em que a reflexão avançar, revelar a profundidade daquilo que, aqui, apenas se anuncia. Assim, o aceno para a historicidade e temporalidade originária da vida deve aparecer, aqui, como apenas um aceno. Muito ainda nos falta para chegarmos a esclarecer o que este aceno está insinuando. 
um objeto. No vivenciar, eu aconteço e, por outro lado, acontece algo comigo (Heidegger, 1987a, p. 75) ${ }^{18}$. As vivências vivem a partir do mais próprio da vida, elas vivem a vida a partir do próprio da vida.

\section{A Vivência da Percepção como Caso Exemplar para a Análise da Intencionalidade}

Se compreendo que cada vivência, por mais cotidiana e modesta que seja, a percepção natural de uma coisa, por exemplo, é um evento onde cada vez acontece a vida, acontece o mundo, onde eu mesmo "aconteço" como serno-mundo-da-vida, então abre-se, para mim, um novo caminho para a compreensão daquilo, a que a descoberta da intencionalidade quer conduzir.

O desafio primeiro deste caminho é deixar vir à fala a vida na sua pregnância. Trazer à fala não significa necessariamente representar e objetivar. Vivendo, somos provocados a deixar vir à fala, na imediaticidade do seu dar-se, a vida mesma, o mundo que ela faz surgir, a cada vez. As palavras devem ser ressonância, vibração da vida mesma. Elas devem provir da vida e, no curso de seu discurso, jamais deixar para traz sua proveniência. Elas hão de expressar as motivações e as tendências da vida. A linguagem ela mesma há de poder acontecer com a vida. O pensar e o falar devem se tornar não objetivantes, ou seja, devem poder vivenciar o viver da vida mesma e, no vivenciar, já compreender e expor, na linguagem, o que aí se abre e se revela. Somente em uma tal intuição hermenêutica podemos seguir o fio condutor da intencionalidade como descoberta fundamental da investigação fenomenológica (Heidegger, 1987a, p. 117).

\subsection{Necessidade de Manter o que, até aqui, Eviden- ciou-se Acerca da Intencionalidade, em Vista de uma Incursão na Região Originária da Vida}

Por agora, estamos acenando para esta região de fenômenos: a vida. Nós tentamos, de início, realizar a fenomenologia como a ciência originária desta região originária e fundamental, que aqui chamamos com o nome, ainda um pouco indeterminado, de vida. Por sua vez, aqui a

\footnotetext{
${ }^{18}$ Estamos traduzindo, aqui, o verbo alemão "es ereignet" por acontece. Tudo porém depende de se entender o verbo "acontece" não na indiferença do "ocorre". A palavra evento quer se referir aqui ao acontecer como inauguração de uma nova possibilidade da vida mesma. É assim que um poeta canta: “... E da minha infinita tristeza aconteceu você" (Jobim). O verbo "er-eignen” parece sugerir que "Ereignis" é o que faz com que algo seja propriamente o que é, o que pro-voca algo a ser o seu próprio ("eigen”) ser. Esta palavra, que terá um peso decisivo no pensamento de Heidegger a partir dos anos trinta, aqui aparece de modo ainda não determinado em sua profundidade, amplidão e originariedade. Mas o modo como ela aparece aqui pode ser o pressentimento do que jaz mais profundamente e que já de algum modo se anuncia neste nível da reflexão fenomenológica.
}

palavra ciência não deve, certamente, ter nada a ver com objetivação ou com construção teorética, já que esta região não se deixa objetivar e toda tentativa de sistematização, de construção teorética, soa arbitrária e acaba fechando o acesso aos fenômenos, em vez de abri-los. Trata-se, portanto, não de uma ciência positiva, ôntica, mas de uma ciência fundamental, ontológica.

A fim de fazer uma incursão nesta região originária da vida nós queremos seguir o fio condutor daquilo, que foi anunciado inicialmente como estrutura das vivências da vida, que se dá, de modo imediato, na nossa experiência: a intencionalidade. Nós tentamos uma compreensão mais aprofundada do seu sentido mais próprio e da sua constituição.

Dizíamos que cada vivência, cada ato ou comportamento, é caracterizado pela intentio, ou seja, pelo dirigirse a alguma coisa. Dizíamos também que este dirigir-se-a tem o modo de ser de um mirar a alguma coisa e de um ser consciência de alguma coisa. Assim, o representar é representar de alguma coisa, a recordação é recordação de alguma coisa, esperar, amar, odiar são sempre esperar, amar, odiar alguma coisa. Já dissemos que isto pode soar como uma imensa banalidade. Pode também ser tomado como uma mera tautologia. Contudo, já no primeiro passo da nossa investigação, começamos a descobrir que aí se esconde uma estrutura peculiar, a priori, de toda vivência, a estrutura do referimento intencional. É preciso abordar essa estrutura, guardando sempre o cuidado de não entender a intencionalidade como relação indeterminada de algo psíquico com algo físico. E alertados para a indicação de que o que chamamos de vivência nada tem a ver com a ocorrência de algo psíquico dentro de uma "cápsula" chamada consciência, tentemos agora seguir de modo mais concreto e explícito o fio condutor da intencionalidade.

\subsection{O Caso Exemplar da Percepção Natural Concreta}

Tentemos isto partindo de um caso exemplar, mais facilmente acessível, de comportamento ou vivência intencional: uma percepção natural concreta, a saber, de uma cadeira, que se encontra, aqui, em meu quarto. De fato, esta vivência é muito cotidiana e facilmente acessível: não preciso de um esforço considerável para perceber esta cadeira que se encontra em meu quarto. Todas as vezes que eu entro nele eu a noto ali, ainda que eu não me interesse especificamente por ela. Às vezes ela se encontra em meu caminho, e eu preciso arredá-la para poder passar ou para poder pegar um livro que se encontra na estante por detrás da cadeira. Portanto, nada de extraordinário. E, no entanto, talvez não seja fácil assim descrever a percepção desta cadeira. Toda a dificuldade, com efeito, está em ver de modo simples o que nesta simples percepção se dá e manter o que se viu em toda a análise, a qual não deve ficar no mero relevamento ônti- 
co e empírico da cadeira e do estado de coisas descoberto pela percepção, mas deve partir para uma consideração ontológica, ou seja, uma consideração a respeito do ser, da estrutura a priori da percepção mesma, enquanto ato, comportamento, ou vivência intencional.

Além disso, é preciso trazer à fala a percepção na sua "naturalidade" e "concretude". Com "naturalidade" não entendemos aquilo que uma visão naturalística da percepção põe em relevo, mas justamente o contrário. Uma investigação da audição ou da visão, por exemplo, numa perspectiva naturalística, realizada em laboratório, seria um modo mediato de abordagem da percepção; não só: mediato e artificial, técnico, reconstruído. Tal método não nos abriria o acesso ao que constitui o sentido intencional da percepção, pois, na sua impostação fisicista, já ignorou totalmente que visão e audição são dotadas de caráter intencional. Somente se conseguirmos manter um olhar fenomenológico para o que se mostra de modo natural e imediato na percepção, a partir da percepção e como percepção, é que conseguiremos também trazer à fala, de modo apropriado, o que se dá como o fenômeno, a coisa mesma da percepção. E o fenômeno da percepção é sempre algo de concreto. Seria, por sua vez, errôneo prejulgarmos aquilo que deve significar, aqui, concretude. Ninguém duvida de que o descoberto pela percepção é sempre algo de concreto e de que a percepção mesma é uma vivência concreta que fazemos constantemente, ao menos em estado de vigília. Mas não podemos, de antemão, decidir qual é a envergadura do que a percepção descobre. É possível que esta envergadura seja muito maior do que a que usualmente atribuímos à percepção, restringindo-a à apreensão de qualidades primárias que se apresentam nos objetos tornados acessíveis através dos cinco sentidos. Pode ser que a percepção não se restrinja ao que, de modo geral, chamamos de "sensível”, mas, de alguma maneira, tenha a ver também com o que se convencionou chamar de "inteligível". Pode ser que tenha a ver não somente com "sensações", mas mesmo com "sentimentos”. Tudo isto, porém, deve ficar, no estado atual da nossa reflexão, em aberto. Qual é a envergadura e a originariedade da percepção só a percepção mesma pode nos revelar. Não é, pois, partindo de um conceito de percepção, definido de antemão, que nós vamos poder saber em que medida a percepção seja um "comportamento" fundamental para a nossa vida e qual seria a sua possibilidade de abertura e de descobrimento do real. É preciso, pois, seguir aquilo que se mostra na percepção sem restringir de antemão os seus limites.

Não obstante, somos forçados a partir de um modo de percepção que seja inteiramente cotidiano. Trata-se de tomar em consideração, num olhar fenomenológico, a percepção tal como se dá de início e na maior parte das vezes. A percepção natural, se me atenho ao modo como nela vivo, se me movo em meu mundo, não é um observar autônomo, isolado, um estudar as coisas, suas "propriedades”, sua “configuração”. Na verdade, a percepção natural emerge em um concreto e prático lidar com as coisas, no freqüentá-las cotidiano. No cotidiano, a percepção não é autônoma: eu não percebo por e para perceber, mas para orientar-me, para abrir-me um caminho, para atravessar a rua, para fazer qualquer coisa: preparar a comida, lavar a roupa, proteger-me das intempéries, manusear um apetrecho, produzir uma obra, etc. De início e na maioria das vezes, portanto, a percepção é uma forma totalmente natural de levar em conta as coisas, um modo no qual eu estou continuamente vivendo, em infindos pequenos gestos do cotidiano (Heidegger, 1994b, p. 37-38).

\subsection{A Percepção como Intentio}

A percepção é uma intentio, um ato, um comportamento, uma vivência intencional. Nossa tendência é de intepretar, de modo grosseiro, a percepção como se fosse uma ocorrência psíquica, algum processo, algo que se dá "dentro de mim", ao qual corresponde, entretanto, algo "fora de mim”, como uma coisa real física. Segundo esta interpretação a percepção seria uma relação, especificamente, uma coordenação entre a realidade da consciência (o sujeito) e a realidade da coisa externa à consciência (o objeto). A intencionalidade seria uma coordenação entre um fenômeno psíquico (imanente) e um objeto físico (transcendente) $)^{19}$.

Todavia, não é necessário que a percepção seja uma relação entre a consciência e algo físico, "externo" à consciência. É o caso, por exemplo, de uma alucinação. Estou em meu quarto e, de repente, vejo uma bicicleta voando sobre minha cabeça. Neste caso, ao processo psíquico não corresponde nenhum objeto real, dá-se uma percepção sem que surja uma relação com alguma coisa fora da percepção mesma. O mesmo caso é o de uma percepção falaz: andando pela estrada vejo um homem que me vem ao encontro; quando chego mais perto, vejo que não era um homem, mas uma árvore. Também aqui falta o objeto, que presumivelmente era o percebido. A percepção, qualquer que seja, mesmo uma percepção presumida, falaz, ilusória, é sempre intencional. Não é necessário que o objeto intencional seja real, para que se dê uma percepção como tal e para que esta seja intencional. Já a percepção presumida é um ato intencional: um dirigir-se a alguma coisa, no caso, um dirigir-se a um percebido presumido. Não é assim que uma percepção seja intencional só graças ao fato de que um elemento físico entre em relação com o psíquico e não seja mais intencional se este real não existisse, mas é a percepção em

\footnotetext{
${ }^{19}$ Daí surge o problema epistemológico, a saber, a pergunta sobre como é que o psíquico, saindo de si, alcança o âmbito físico, como é que, a um processo psíquico corresponde um objeto real. Trata-se de um pseudo-problema, que se dissolve tão logo se evidencia que seus pressupostos já são o resultado de uma compreensão equivocada do fenômeno da percepção (relação entre dentro e fora, psíquico e físico, imanente e transcendente), compreensão que parte do dogma da relação sujeito-objeto.
} 
si mesma, autêntica ou falaz, "normal" ou "patológica", a ser intencional. Com outras palavras, intencionalidade não é uma propriedade que se acrescentaria à percepção em certos casos, mas a percepção é por natureza, $a$ priori, intencional, prescindindo do fato de o percebido ser realiter simplesmente dado ou não. E justamente porque a percepção como tal é um dirigir-se a alguma coisa, porque a intencionalidade constitui a estrutura do comportamento mesmo, é que pode dar-se algo como a percepção falaz e a alucinação ${ }^{20}$. Enquanto vivência, a percepção é sempre intencional, a intencionalidade é uma estrutura a priori, essencial, necessária, uma condição sine qua non da percepção como tal (Heidegger, 1994b, p. 39-40). Dito de outro modo, com o termo intencionalidade não pensamos uma relação intermitente e objetiva, que entra em forma de acréscimo entre uma coisa física e um processo psíquico, mas a estrutura de um comportamento como comportamento-para-com, como dirigir-se-a. Assim, a intencionalidade não é uma "propriedade" desta ou daquela percepção, da percepção disto ou daquilo, mas da percepção mesma, do perceber como tal (Heidegger, 1994b, p. 48).

\subsection{Do "Dirigir-se-a" ao "a-que" do Direcionamento Intencional - Seguindo o Caso exemplar da Per- cepção: do Perceber ao Percebido.}

Acontece, porém, que, ao afirmarmos que o dirgirse-a-alguma-coisa constitui o traço característico do ato ou vivência intencional, não estamos dizendo tudo; estamos apenas abrindo uma direção de investigação. Através desta indicação, apenas delineamos um primeiro momento da estrutura intencional e isto numa formalidade vazia, ainda distante de mostrar toda a sua pregnância. Para tentar deixar desabrochar a estrutura intencional na sua pregnância tentemos seguir o dirigir-se-a

\footnotetext{
${ }^{20}$ A respeito de uma análise fenomenológica da alucinação podem-se confrontar as anotações de Medard Boss (29 de Novembro de 1961) após um seminário sobre este tema, realizado com Heidegger. Ali se analisa brevemente um caso de alucinação de um paciente esquizofrênico, que nunca tinha percebido a si mesmo a não ser como homossexual. Algumas indicações gerais são dadas no contexto da breve, e certamente não exaustiva, análise do caso. Existem diversos modos de presença daquilo que se dirige a nós a partir do aberto de nosso mundo: percepção, lembrança, expectativa, imaginação, etc. Também a alucinação é um modus de presença daquilo que nos vem ao encontro no mundo. Ali se diz, por exemplo, que o alucinado só pode ver seu mundo em um ser-presente de todas as datidades, atual, perceptível de modo sensorial, porque ele não pode lidar com o presente e o ausente, porque ele não pode se movimentar livremente em seu mundo. Para ele o ausente deve se tornar presença e o presente deve ser intensificado de tal modo que apareça de modo visível, pois o visível é a forma mais elevada de presença. Outra indicação interessante é a de que, para compreender as alucinações, não se deve partir da diferenciação entre "real" e "irreal", mas da investigação do caráter de relação com o mundo, na qual, exatamente o paciente, cada vez, está. Pergunta-se se não seria a intensidade desta relação do paciente, o seu banimento nela, a falta de liberdade na mesma, o que empresta à coisa alucinada o caráter de algo perceptível sensorialmente (Heidegger, 1987b, p. 195-196).
}

próprio do caso exemplar da percepção natural de uma coisa. Só que agora, em vez de ficarmos olhando para o dirigir-se-a, vamos considerar fenomenologicamente o a quê deste dirigir-se, aquilo que de maneira incoativa, ainda indeterminada e sujeita a equívocos, chamamos de objeto intencional ${ }^{21}$.

Trata-se, portanto, de investigar o percebido desta percepção escolhida como caso exemplar: a percepção natural de uma coisa. Do que se trata? De uma cadeira. O que vejo, quando olho para uma cadeira? A resposta é simples e desconcertante, mas não desprovida de uma riqueza fenomenal: quando eu olho para a cadeira eu vejo a cadeira mesma! O que quer dizer esta trivialidade? Que quando eu percebo a cadeira eu não estou vendo "representações" da cadeira, não estou apreendendo nenhuma imagem da cadeira, não estou advertindo sensações da cadeira, mas simplesmente estou vendo a cadeira, eu $a$ vejo simplesmente - vejo ela mesma.

Mas, insisto nesta pergunta e indago: o que vejo quando vejo esta cadeira? Se respondo, de modo bem natural, sem construções teóricas e sem artifícios experimentais, então eu acabo dizendo a "história" desta cadeira ${ }^{22}$. Trata-se de uma "história" bem determinada, ainda que sem importância, na qual ela se dá constantemente, na qual ela é cotidianamente presente: trata-se de uma cadeira que se encontra em meu quarto, no meu ambiente de trabalho, uma cadeira que reservo para que as pessoas que vêm conversar comigo possam se sentar e se sentir à vontade, uma cadeira que agora precisamente não está sendo usada por alguém e que, devido ao meu jeito meio desarrumado, está sendo usada como suporte para alguns livros, que não estou usando imediatamente, mas de que preciso a qualquer momento e que, por isso, não quero deixar na estante. Esta cadeira faz parte do meu ambiente de trabalho e também da história de minhas relações. Nela se sentaram as pessoas que acompanho no meu serviço de educador ou pessoas amigas que vieram me visitar e "bater um papo" comigo. Algumas destas conversas foram descontraídas, outras foram tensas. E ali está ela, a cada dia, às vezes me ajudando, às vezes me atrapalhando na minha movimentação pelo quarto. Ali está ela, dando-se cada vez na sua serventia. Ali está ela, enquanto puder ser usada, enquanto não for substituída por outra. Aquilo que é percebido nesta percepção "natural" nós o definimos como coisa do mundo circunstante (Heidegger, 1994b, p. 49).

\footnotetext{
${ }^{21}$ O equívoco mais contumaz, aqui, seria o de interpretar a relação entre referimento intencional e objeto intencional a partir da relação sujeito-objeto, a qual se apresenta como mais vazia ainda e cuja importância é decidida através da primazia do teorético no contexto da discussão epistemológica.

${ }^{22}$ Uso, aqui, a palavra "história", num sentido muito amplo, como no cotidiano, quando digo, por exemplo: "conta-me a história desta bicicleta estragada”, ou ainda, "que história é esta, de a máquina de lavar não estar funcionando mais". A coisa do mundo circunstante não tem, propriamente, um história. O ente historial, propriamente, somos nós mesmos, nosso mundo da vida. As coisas que, aí, vêm ao nosso encontro só têm uma história porque são intramundanas.
} 
Confirma-se, aqui, o que dizíamos anteriormente: em cada vivência acontece o mundo, acontece a vida. Na vivência da percepção desta cadeira o mundo acontece, à medida que, ao vê-la, eu já a vejo como coisa do mundo circunstante, ou melhor, como coisa-de-uso, pertencente ao meu mundo circunstante. Esta cadeira aparece como o percebido da minha percepção a partir da experiência que eu faço, que eu estou continuamente fazendo, da vida.

\subsection{A Estrutura do Dirigir-se-a, Enquanto Constitutivo da Vida Mesma - O Acontecer da Vida como Abertura de Mundo e a Tríplice Mundanidade do Mundo: Mundo Circunstante, Mundo Compartilha- do e Mundo Próprio}

A experiência da vida é sempre fáctica, isto é, historial. Na experiência se dá cada vez um encontro, um confronto, com o experimentado. No entanto, aquilo que encontro, aquilo com que confronto na experiência da vida, ou seja, a vida mesma, não é nunca um objeto, uma coisa que está aí à minha frente. A vida se dá, na minha experiência, de modo muito mais imediato, próximo, originário, em todas e em cada uma das vivências.

$\mathrm{Eu}$, tu, nós vivemos sempre em uma determinada $d i-$ reção. Tal direção pode ser implícita ou explícita, pode me ser conhecida ou desconhecida, pode se tornar tema da minha reflexão ou pode permanecer somente uma orientação prática, operativa, pode ser latente ou pode ser patente, pode ser mais fundamental ou menos fundamental. Ela pode mudar. Talvez mude muitas vezes no curso de uma história. Múltiplas são as tendências da vida. Tal multiplicidade já se mostra no meu cotidiano - a minha vida cotidiana já se dispersou em tantos e tantos comportamentos: eu me acordo, faço exercícios físicos, medito, oro, me alimento, trabalho, me encontro com pessoas, leio, escrevo, atendo telefone, ouço música, saio para passear, dou aulas, faço conferências, me canso, durmo. Sempre eu estou em alguma parte, sempre eu estou me demorando junto de alguma coisa: agindo ou sofrendo e, enquanto ajo ou sofro, percebendo, recordando, imaginando, pensando, alegrando-me ou entristecendo-me, satisfazendo-me ou sentindo-me contrariado, querendo e desejando, ansiando, tendendo para isto ou para aquilo.

Na experiência fáctica da vida eu tenho sempre um determinado âmbito, ainda que variável, ora mais amplo, ora mais estreito, de "coisas" que me solicitam, que reivindicam a minha vida, continuamente ou de tempos em tempos, ora deste modo ora de outro, "coisas" que fazem parte da minha vida, estão dentro dela, se dão no seu contexto. Também aí se dão círculos de convivência, domésticos ou públicos, onde aparecem as pessoas com quem me encontro, com quem convivo, de modo mais ou menos intenso, da mera indiferença do passar ao lado na mesma rua desta cidade, do sentar-me ao lado no mes- mo ônibus, até a comunhão mais profunda de uma amizade, de uma afeição verdadeira. Ao longo do tempo, vários são os encontros e desencontros com as pessoas. Algumas passam, outras ficam como amigos perenes. Suas vidas mudam, minha vida muda, nossas relações mudam, mas a amizade permanece. Também aí, dá-se o encontro comigo mesmo, o confronto com minhas convicções e idéias, com minha concepção acerca do sentido do meu viver; aí, eu faço novas experiências; sou lançado para lá e para cá na oscilação de minhas tendências opostas; sinto a vida, ora como um prazer, ora como um peso insuportável; alegro-me, angustio-me; entusiasmome, entedio-me. "Na experiência fáctica, historial, da vida, a vida está sempre aí, porém nunca como objeto, coisa ou processo, mas sempre como evento, acontecimento do mundo" (Heidegger, 1993, p. 32-33).

A vida está sempre se dando, acontecendo como abertura de mundo. O experimentado na experiência da vida, o vivenciado em todas e em cada uma das vivências não se dá nunca como objeto, mas se dá sempre como mundo. Mundo é ali onde se pode viver. Num objeto não se pode viver. $\mathrm{O}$ mundo é sempre mundo da vida. E a vida é sempre vida no mundo ${ }^{23}$.

Grosso modo, por sua vez, o mundo se articula em três dimensões, cada uma se constituindo como âmbito de aparição de fenômenos variados, dimensões distintas, mas que se confluem continuamente uma na outra, jamais separáveis entre si: o mundo circunstante, ou seja, o mundo enquanto meio, milieu, ambiência; o mundo compartilhado, enquanto mundo da con-vivência, o contexto em que se dá o encontro e a história dos relacionamentos com as pessoas, próximas ou distantes, onde também se instauram os círculos de convivência, domésticos ou públicos, a condição da possibilidade de comunidade e sociedade, respectivamente, da ereção de instituições sociais, políticas...; o mundo próprio, ou seja, o mundo enquanto a totalidade de sentido, em que vivo, a partir de que eu encontro a mim mesmo, compreendo-me, trago-me à fala, assumo-me, faço-me, determino-me, individuo-me (Heidegger, 1993, p. 33).

Nossa vida é nosso mundo. Estamos aí como imersos na vida. Podemos nos sentir como que aprisionados ou soltos, impelidos a lutar ou resignados, fortunados ou desventurados. Podemos nos revoltar contra este fato ou podemos nos alegrar com ele. Contudo, do fato inexorável de que estamos vivos e de que tudo aquilo que fazemos é sempre um ato de responsabilização por este mesmo fato - disso não podemos nos evadir. Mesmo um ato de evasão da vida, um ato contra a vida é já um ato a partir da vida, o ato de um vivente.

Nossa vida é o mundo no qual vivemos. Dizemos que a vida corre. Não podemos deter o tempo da vida. O fluir

\footnotetext{
${ }^{23}$ Mesmo se a religião fala de outra vida, esta outra vida não pode ser senão uma vida num outro mundo, num mundo futuro, "num novo céu e numa nova terra", onde as coisas velhas terão dado lugar às coisas novas.
} 
da vida é constante. Mas nossa vida só é vida enquanto vive em um mundo. A vida encontra em cada momento de seu decurso um certo quê do mundo. Ela é a cada momento o acontecer do mundo. A vida não se encontra fora do mundo e o mundo fora da vida, como um espaço vazio que precisa ser preenchido. A vida vive sempre de algum modo em seu mundo. O mundo só é mundo a partir do acontecimento da vida.

\section{Referências}

Descartes, R. (1979). Meditações (J. Guinsburg \& B. Prado Júnior, Trads.). São Paulo: Abril Cultural.

Heidegger, M. (1987a). Zur Bestimmung der Philosophie, Gesammtausgabe - Band 56/57, Vittorio Klostermann, Frankfurt am Main.

Heidegger, M. (1987b). Zollikoner Seminare - Protokolle, Gespräche, Briefe (ZollS), heraugegeben von Medard Boss, Gesamtaugabe - Band 89, Vittorio Klostermann, Frankfurt am Main.

Heidegger, M. (1994a). Einführung in die phänomenologische Forschung, Gesamtausgabe (GA) Band 17, Vittorio Klostermann, Frankfurt am Main.

Heidegger, M. (1994b). Prolegomena zur Geschichte des Zeitbegriffs (PGZ), Gesamausgabe - Band 20, Vittorio Klostermann, Frankfurt am Main, p. 37-38.

Heidegger, M. (1993). Grundprobleme der Phänomenologie, Gesamtausgabe, Band 58, Vittorio Klostermann, Frankfurt a.M.

Husserl, E. (1993). Ideen zu einer reinen Phänomenologie und phänomenologischen Philosophie, Estes Buch, Max Niemeyer, Tübingen.

Husserl, E. (2006). Idéias para uma fenomenologia pura e uma filosofia fenomenológica: introdução geral à fenomenologia pura (M. Suzuki, Trad.). Aparecida, SP: Idéias \& Letras.

Marcos Aurélio Fernandes - Graduado em Filosofia pela Universidade São Francisco (1991), com Mestrado e Doutorado em Filosofia pela Pontifícia Universidade Antonianum (2000 e 2003). Atualmente é Professor Doutor da Universidade Católica de Brasília, lotado no Centro de Reflexão sobre Ética e Antropologia da Religião. Endereço Institucional: Universidade Católica de Brasília (Centro de Reflexão sobre Ética e Antropologia). QS. 07, Lote 01, EPCT Areal (Águas Claras). CEP 71.966-700 - Brasilia, DF, Brasil. Email: framarcosaurelio@hotmail.com 